\title{
ANALISIS KERENTANAN BANJIR DAN PENANGGULANGAN BENCANA DI DAERAH ALIRAN SUNGAI CODE KOTA YOGYAKARTA
}

\author{
(THE VULNERABILITY ANALYSIS OF FLOOD AND FLOOD DISASTER \\ MANAGEMENT IN CODE WATERSHED, YOGYAKARTA)
}

\author{
Nurhadi, Dyah Respati Suryo Sumunar, dan Nurul Khotimah \\ Fakultas Ilmu Sosial Universitas Negeri Yogyakarta \\ Jl. Colombo No. 1 Yogyakarta \\ e-mail: geonurhadi@gmail.com
}

\begin{abstract}
Abstrak
Penelitian ini bertujuan untuk mengetahui: (1) kerentanan bencana banjir lahar dingin di sepanjang bantaran Sungai Code Kota Yogyakarta dan (2) arahan penanggulangan bencana banjir lahar dingin di sepanjang bantaran Sungai Code Kota Yogyakarta. Penelitian dilaksanakan di sepanjang bantaran Sungai Code yang berada di Kota Yogyakarta sejak bulan Mei hingga Oktober 2013. Populasi penelitian adalah sepanjang bantaran Sungai Code yang berada di kawasan Kota Yogyakarta. Sampel penelitian adalah kawasan sepanjang bantaran Sungai Code yang terkena dan tidak terkena dampak banjir lahar dingin. Data dikumpulkan dengan metode dokumentasi, wawancara, dan cek lapangan. Teknik analisis data adalah analisis kuantitatif dengan tumpangsusun/overlay parameter-parameter banjir berjenjang tertimbang dengan menggunakan SIG. Hasil penelitian menunjukkan bahwa: (1) wilayah di bantaran Sungai Code yang memiliki tingkat kerentanan banjir kategori sedang adalah wilayah Cokrodiningratan dan Gowongan, sedangkan wilayah dengan tingkat kerentanan banjir kategori rentan adalah wilayah Sosromenduran, Suryatmajan, Prawirodirjan, Keparakan, Brontokusuman, dan Sorosutan, (2) arahan penanggulangan banjir dengan perencanaan revitalisasi kawasan permukiman Sungai Code agar lebih terarah dan aman dari bencana, yaitu melalui revitalisasi vertikal dan horizontal
\end{abstract}

Kata kunci: analisis kerentanan, banjir, DAS, Sungai CODE

\begin{abstract}
This study aims to determine: (1) the vulnerability of cold lava flood disaster along the banks of the River Yogyakarta City Code, and (2) the direction of flood disaster management cold lava along the banks of the River Code of Yogyakarta. Research carried out along the banks of the River Code that was in the city of Yogyakarta from May to October 2013. The study population is along the banks of the Code River in the area of the city of Yogyakarta. Samples were along the river bank area code affected and not affected by cold lava flood. Data collected by the method of documentation, interviews, and field checks. The data analysis technique is quantitative analysis with tumpangsusun/ overlay parameters tiered flood weighted using GIS. The results showed that: (1) The area on the banks of the River Code that have medium levels of vulnerability is flooding the medium category and Gowongan Cokrodiningratan region, while the region with the vulnerability
\end{abstract}


of flood prone category is Sosromenduran region, Suryatmajan, Prawirodirjan, Keparakan, Brontokusuman, and Sorosutan, (2) Referral to the revitalization plan for flood prevention Code River settlements to be more effective and safer from disasters, namely through the revitalization of the vertical and horizontal.

Keywords: analysis, vulnerability, flooding, watershed Code

\section{PENDAHULUAN}

Banjir merupakan fenomena alam dimana terjadi kelebihan air yang tidak tertampung oleh jaringan drainase di suatu daerah sehingga menimbulkan genangan yang merugikan. Kerugian yang diakibatkan banjir seringkali sulit diatasi, baik oleh masyarakat maupun instansi terkait. Banjir disebabkan oleh berbagai macam factor, yaitu kondisi daerah tangkapan hujan, durasi dan intesitas hujan, land cover, kondisi topografi, dan kapasitas jaringan drainase.

Banjir dalam bahasa populernya biasa diartikan sebagai aliran atau genangan air yang menimbulkan kerugian ekonomi atau bahkan menyebabkan kehilangan jiwa, sedangkan dalam istilah teknik 'banjir' adalah aliran air sungai yang mengalir melampaui kapasitas tampung sungai tersebut (Hewlett, 1982 dalam Asdak, 2002). Lebih lanjut Siswoko (2002), menyatakan peristiwa banjir merupakan suatu indikasi dari ketidakseimbangan sistem lingkungan dalam proses mengalirkan air permukaan, dipengaruhi oleh besar debit air yang mengalir melebihi daya tampung daerah pengaliran, selain debit aliran permukaan banjir juga dipengaruhi oleh kondisi daerah pengaliran dan iklim (curah hujan) setempat.

Fenomena banjir menjadi pandangan publik yang menyedihkan, banjir dapat terjadi kapan dan dimana saja. Untuk dapat mengidentifikasi resiko banjir yang berpengaruh pada manusia dan lingkungan perlu diketahui penyebab terjadinya. Banjir dan kekeringan adalah masalah yang saling berkaitan dan datang saling menyusul, semua faktor yang menyebabkan kekeringan akan bergulir menyebabkan terjadinya banjir (Maryono, 2005). Lebih lanjut Siswoko (2002) menyatakan bahwa beberapa faktor penyebab banjir yaitu adanya interaksi antara faktor penyebab bersifat alamiah, dalam hal ini kondisi dan peristiwa alam serta campur tangan manusia yang beraktivitas pada daerah pengaliran.

Banjir yang terjadi di Kota Yogyakarta lebih dipengaruhi oleh pendangkalan yang terjadi akibat intensitas sedimen dari hasil erupsi gunung Merapi tahun 2010 di sepanjang aliran Sungai Code. Hal ini mengakibatkan volume badan sungai untuk 
menampung aliran air semakin berkurang sehingga terjadi limpasan atau luapan aliran air di sepanjang aliran Sungai Code sehingga terjadi banjir kiriman. Banjir di Kota Yogyakarta memiliki karakteristik yang berbeda dengan banjir pada lahan alamiah.

Pada kondisi di alam, air hujan yang turun ke tanah akan mengalir sesuai kontur tanah yang ada ke arah yang lebih rendah. Untuk daerah perkotaan pada umumnya air hujan yang turun akan dialirkan masuk ke dalam saluran-saluran buatan yang mengalirkan air masuk ke sungai. Karena aliran sungai Code sudah penuh dengan material hasil erupsi maka limpasan air dari daratan kota juga tidak tertampung ke dalam badan sungai Code sehingga terjadi genangan yang besar. Hal ini terjadi apabila terjadi hujan dengan intensitas yang tinggi di Kota Yogyakarta dan di hulu sungai Code yaitu di wilayah gunung Merapi.

Peristiwa banjir lahar dingin di Kota Yogyakarta akibat meluapnya Sungai Code seperti yang diuraikan di atas merupakan suatu permasalahan yang perlu dikaji secara detil. Salah satu cara untuk mengkaji peristiwa tersebut yaitu dengan pemetaan daerah rawan bencana banjir lahar dingin di sepanjang Sungai Code. Pemetaan daerah rawan bencana ini didasarkan dari beberapa latar belakang peristiwa banjir lahar dingin di sepanjang musim hujan tahun 2011 dan 2012, dan pemetaan profil sungai sepanjang aliran sungai Code yang membelah Kota Yogyakarta.

Pemetaan daerah-daerah yang memiliki tingkat bahaya banjir perlu dilakukan agar pemerintah dapat mengambil kebijakan yang tepat untuk menanggulanginya. Peta merupakan salah satu sarana yang baik dalam menyajikan data dan informasi. Melalui peta dapat diketahui informasi tentang ruang muka bumi yang sebenarnya. Identifikasi kerentanan banjir dengan menggunakan Sistem Informasi Geografis dapat dilakukan dengan cepat, mudah dan akurat. Kerentanan banjir dapat diidentifikasi secara cepat melalui Sistem Informasi Geografis dengan menggunakan metode tumpang susun/ overlay terhadap parameter-parameter banjir, seperti: infiltrasi tanah, kemiringan lereng, dan penggunaan lahan. Melalui Sistem Informasi Geografis diharapkan akan mempermudah penyajian informasi spasial khususnya yang terkait dengan penentuan tingkat kerentanan banjir serta dapat menganalisis dan memperoleh informasi baru dalam mengidentifikasi daerah-daerah yang sering menjadi sasaran banjir.

Salah satu peristiwa yang terjadi pada banjir lahar dingin pada tahun 2011 dan 2012 yang digunakan sebagai dasar pemetaan daerah rawan bencana banjir di Kota Yogyakarta. Pemetaan profil sungai sepanjang aliran Sungai Code akan memberikan gambaran yang meliputi volume 
badan sungai sepanjang aliran Sungai Code sehingga kemampuan daya tampung sungai terhadap debit aliran maksimum yang mampu ditampung oleh aliran sungai tersebut dapat diketahui. Pemetaan profil Sungai Code juga didukung oleh jumlah saluran air dari wilayah perkotaan yang memasok aliran air dari wilayah daratan yang memasuki Sungai Code.

\section{METODE}

Penelitian ini dilaksanakan di sepanjang aliran Sungai Code yang berada di Kota Yogyakarta Provinsi Daerah Istimewa Yogyakarta. Faktor-faktor yang mempengaruhi dalam pemilihan daerah di sepanjang aliran Sungai Code Kota Yogyakarta adalah (1) merupakan daerah sasaran banjir yang terjadi secara periodik; (2) tersedianya data serta informasi spasial dan deskriptif mengenai gambaran umum daerah penelitian; dan (3) penelitian tentang banjir di daerah penelitian belum banyak dilakukan. Kegiatan penelitian ini adalah selama enam bulan, yakni dari bulan AprilSeptember Tahun 2013.

Populasi dalam penelitian ini adalah sepanjang aliran Sungai Code yang berada di kawasan Kota Yogyakarta. Adapun yang menjadi sampel penelitian ini terbagi menjadi dua kategori, yaitu: (1) kawasan sepanjang aliran Sungai Code yang terkena dampak banjir lahar dingin. (2) Kawasan sepanjang aliran Sungai Code yang tidak terkena dampak banjir lahar dingin. Penelitian ini menggunakan dua macam data, yaitu data primer dan data sekunder.

Adapun tahapan dalam pengumpulan data adalah sebagai berikut: pertama, data primer, yaitu data hasil wawancara dengan penduduk di lokasi kerentanan banjir tentang karakteristik banjir yang meliputi periode ulang, lama genangan, dan kedalaman banjir. Data ini digunakan untuk memperkuat hasil analisis kuantitatif. Kedua, data sekunder yang meliputi: (1) data curah hujan time series antara tahun 2000 sampai 2012; (2) Peta Rupa Bumi Indonesia skala $1: 25.000$ lembar Yogyakarta; (3) peta geologi dan foto udara lembar Yogyakarta; (4) petapeta tematik: peta kemiringan lereng, peta infiltrasi tanah, peta bentuk lahan, dan peta penggunaan lahan; dan (5) cek lapangan, yang dilakukan dengan mengambil beberapa sampel yang dirasa dapat mewakili dari seluruh populasi.

Data-data yang digunakan dalam penelitian ini diperoleh dari peta Rupa Bumi Indonesia (RBI) skala $1: 25.000$ lembar Yogyakarta. Informasi yang terdapat dalam peta RBI atau kemampuan tanah bermacammacam. Untuk memilih sebuah informasi data yang diinginkan harus dilakukan dengan proses seleksi. Tujuannya adalah untuk mendapatkan informasi data yang diinginkan seperti informasi penggunaan 
lahan, kemiringan lereng, dan tekstur tanah. Metode analisis yang digunakan untuk mencapai tujuan penelitian adalah metode analisis kuantitatif dengan menggunakan metode pendekatan analisis tumpang susun/overlay parameter-parameter banjir berjenjang tertimbang dengan menggunakan Sistem Informasi Geografis (SIG). Overlay dilakukan dengan input tiga peta tematik, yaitu peta kemiringan lereng, peta infiltrasi tanah, dan peta penggunaan lahan. Ketigapeta tersebut merupakan parameter-parameter kerentanan banjir dalam penelitian ini.

Overlay dilakukan tidak hanya melibatkan unsur spasial dari masingmasing parameter kerentanan banjir saja, tetapi tidak kalah pentingnya adalah overlay atribut yang menyertainya. Sebagian besar parameter-parameter kerentanan banjir berupa data spasial yang bersifat kualitatif. Untuk melakukan proses analisis, masingmasing parameter perlu ditransformasikan ke dalam bentuk kuantitatif dalam bentuk pengharkatan dan pembobotan.
Pemberian bobot pada masing-masing parameter atau variabel berbeda-beda, yaitu dengan memperhatikan seberapa besar pengaruh parameter-parameter tersebut terhadap terjadinya banjir. Semakin besar pengaruh parameter tersebut terhadap banjir maka nilai bobotnya juga besar. Sebaliknya jika pengaruhnya kecil maka nilai bobotnya juga kecil (lihat Tabel 1-3).

Metode aritmatika yang digunakan dalam proses overlay dapat berupa penambahan, pengkalian dan perpangkatan. Untuk pembuatan Peta Kerentanan Banjir metode aritmatika yang digunakan pada proses overlay dari parameter-parameter kerentanan banjir berupa metode pengkalian antara harkat dengan bobot pada masingmasing parameter kerentanan banjir. Pembuatan nilai interval kelas kerentanan banjir bertujuan untuk membedakan kelas kerentanan banjir antara yang satu dengan yang lain. Berikut rumus yang digunakan untuk membuat kelas interval.

$K i=\frac{X_{t}-X_{r}}{K}$

Tabel 1

Klasifikasi Infiltrasi Tanah

\begin{tabular}{|c|c|c|c|c|}
\hline No & Tekstur & Harkat & Bobot & Skor \\
\hline 1 & Halus & 5 & & 15 \\
\hline 2 & Agak Halus & 4 & & 12 \\
\hline 3 & Sedang & 3 & 3 & 9 \\
\hline 4 & Agak Kasar & 2 & & 6 \\
\hline 5 & Kasar & 1 & & 3 \\
\hline
\end{tabular}


Tabel 2

Klasifikasi Kemiringan Lereng

\begin{tabular}{lcccc}
\hline No & Slope $(\%)$ & Harkat & Bobot & Skor \\
\hline 1 & $0-2$ & 5 & & 25 \\
2 & $2-7$ & 4 & & 20 \\
3 & $7-14$ & 3 & 5 & 15 \\
4 & $15-21$ & 2 & & 10 \\
5 & $>21$ & 1 & & 5 \\
\hline
\end{tabular}

Tabel 3

Klasifikasi Penggunaan Lahan

\begin{tabular}{llccc}
\hline No & \multicolumn{1}{c}{ Penggunaan Lahan } & Harkat & Bobot & Skor \\
\hline 1 & Lahan terbuka, sungai waduk, rawa & 5 & & 10 \\
2 & Permukiman, kebun campuran, tanaman & 4 & & 8 \\
3 & pekarangan & & 2 & 6 \\
4 & Pertanian, sawah, pekarangan & 3 & & 4 \\
5 & Perkebunan, semak & 2 & & 2 \\
\hline
\end{tabular}

Keterangan:

$\mathrm{Ki}=$ kelas interval

$\mathrm{Xt}=$ data tertinggi

$\mathrm{Xr}=$ data terendah

$\mathrm{K}=$ jumlah kelas yang diinginkan

Nilai kelas interval

Data tertinggi $=50$

Data terendah $=10$

Jumlah kelas $=5$

$\mathrm{Ki} \quad=(50-10) / 5=8$

Nilai interval ditentukan dengan pendekatan relatif dengan cara melihat nilai maksimum dan nilai minimum tiap satuan pemetaan, kelas interval didapatkan dengan cara mencari selisih antara data tertinggi dengan data terendah dan dibagi dengan jumlah kelas yang diinginkan. Kerentanan banjir dalam penelitian ini terbagi menjadi lima kelas tingkat kerentanan, yaitu sangat rentan, rentan, cukup rentan, agak rentan, dan tidak rentan. Secara lebih rinci dapat dilihat pada Tabel 4.

\section{HASIL DAN PEMBAHASAN}

Kawasan rawan banjir lahar hujan di bantaran Kali Code Kota Yogyakarta diukur dengan cara penskoran yang meliputi parameter infiltrasi, kemiringan lereng, dan penggunaan lahan di bantaran Kali 
Tabel 4

Pembagian Kelas Tingkat Kerentanan

\begin{tabular}{clc} 
Banjir & & \\
\hline No & Tingkat Kerentanan & Skor \\
\hline 1 & Sangat rentan & $43-50$ \\
2 & Rentan & $>34-42$ \\
3 & Sedang & $>26-34$ \\
4 & Kurang Rentan & $>18-26$ \\
5 & Tidak Rentan & $10-18$ \\
\hline
\end{tabular}

Code. Parameter infiltrasi terukur dengan pengharkatan yang dipengaruhi oleh tekstur tanah, pengharkatan kemiringan lereng dengan pengukuran kemiringan lereng, dan dari peta Kemiringan Lereng (Gambar 1). Pengharkatan penggunaan lahan didasarkan pada jenis penggunaan lahan yang terdapat di lokasi sampel dan pada Peta Penggunaan Lahan (Gambar 2). Kondisi bantaran Sungai Code di kawasan perkotaan Yogyakarta disajikan pada Tabel 5.

Penskoran Kawasan Rawan Bencana Banjir Lahar Hujan di Kota Yogyakarta dengan mengambil delapan titik sampel, yaitu di Cokrodiningratan, Gowongan, Sosromenduran, Suryatmajan, Prawirodirjan, Keparakan, Brontokusuman, dan Sorosutan, ada dua kategori rawan bencana banjir lahar hujan yaitu sedang dan rentan bencana.Wilayah yang mempunyai kategori sedang adalah di wilayah Cokrodiningratan dan Gowongan.

Gambar 1. Peta Kemiringan Lereng Kota Yogyakarta

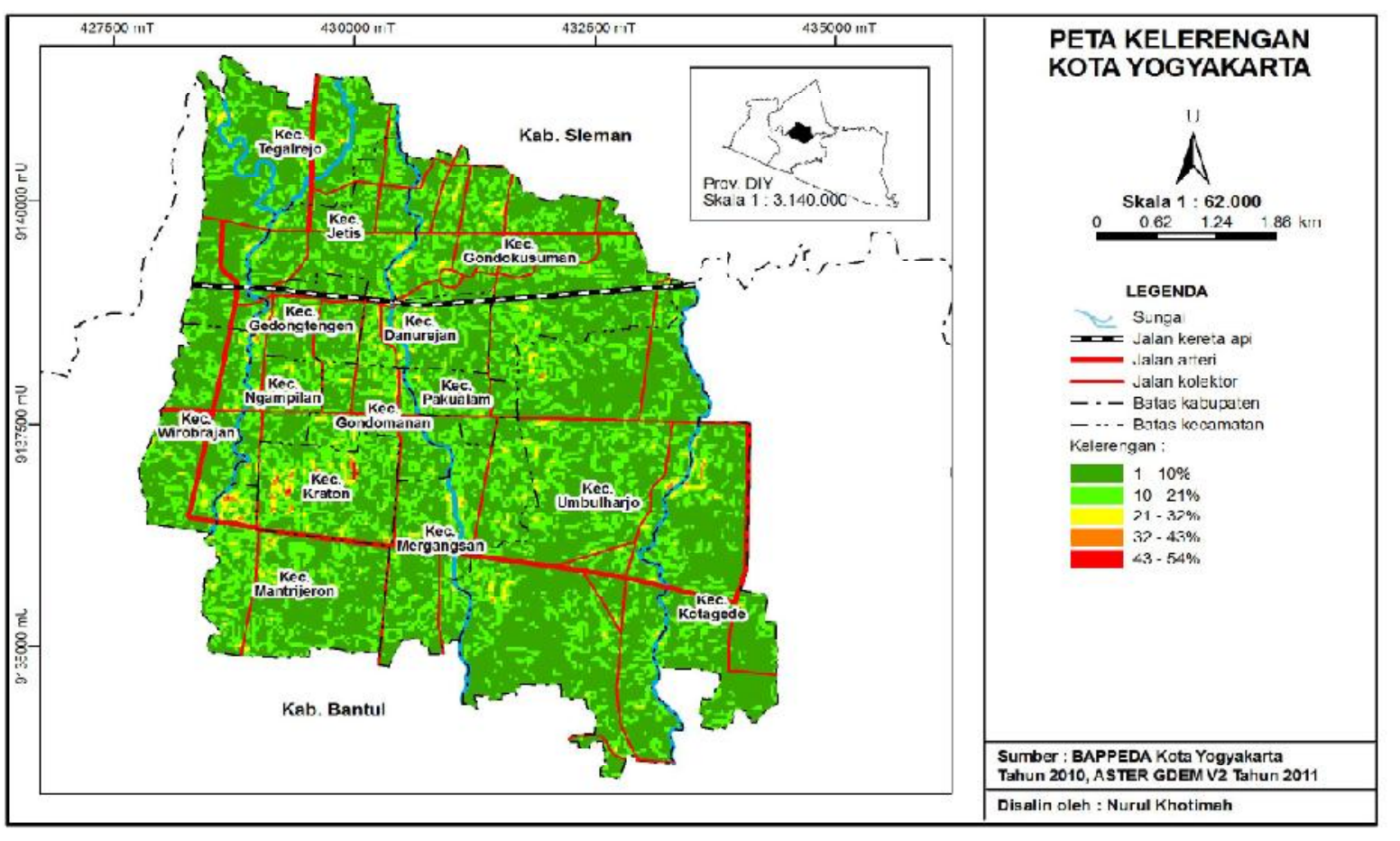




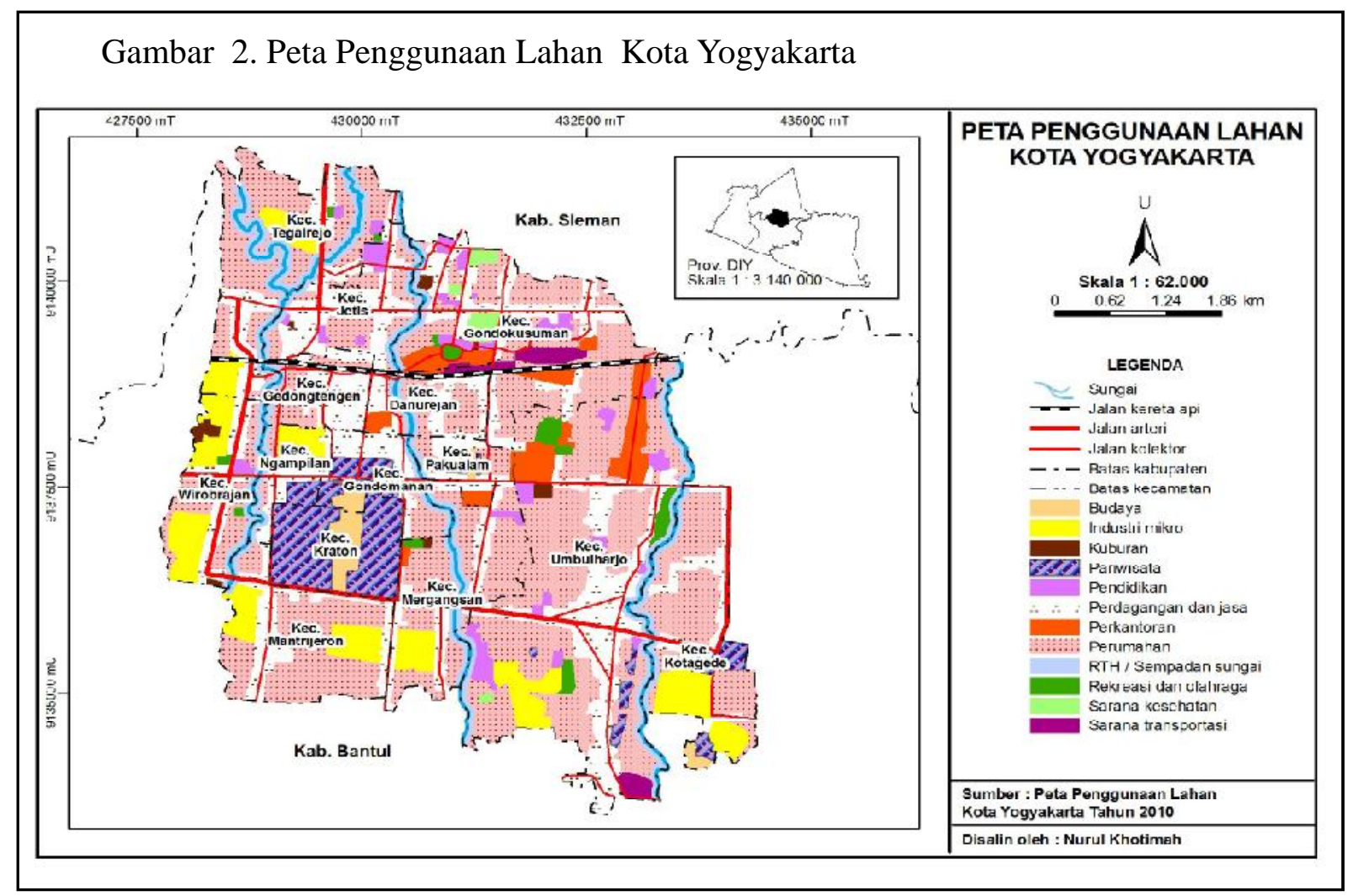

Tabel 5

Kondisi Bantaran Sungai Code di Kawasan Perkotaan Yogyakarta

\begin{tabular}{|c|c|c|}
\hline Kawasan & Tapak & Kenampakan \\
\hline Sub kawasan Code Utara & $\begin{array}{l}\text { Sempadan sebagai kawasan } \\
\text { lindung sungai sungai } 10-15 \\
\text { m masih cukup }\end{array}$ & $\begin{array}{l}\text { Suasana alami sungai } \\
\text { Code Utara di perkotaan } \\
\text { Yogyakarta masih kuat }\end{array}$ \\
\hline Sub kawasan Code Tengah & $\begin{array}{l}\text { Sempadan sebagai kawasan } \\
\text { lindung sungai 10-15 m sudah } \\
\text { tidak terpenuhi }\end{array}$ & $\begin{array}{l}\text { Sempadan sungai sebagai } \\
\text { akses dan tapak bangunan } \\
\text { yang padat }\end{array}$ \\
\hline Sub kawasan Code Selatan & $\begin{array}{l}\text { Sempadan sebagai kawasan } \\
\text { lindung sungai 10-15 m sudah } \\
\text { tidak terpenuhi }\end{array}$ & $\begin{array}{l}\text { Sempadan sebagai kawasan } \\
\text { lindung sungai 10-15 m tidak } \\
\text { terpenuhi }\end{array}$ \\
\hline
\end{tabular}

Sumber: data lapangan tahun 2013

Sedangkan yang mempunyai kategori rentan adalah wilayah Sosromenduran, Suryatmajan, Prawirodirjan, Keparakan,
Brontokusuman, dan Sorosutan. Bagian utara Kota Yogyakarta yaitu wilayah Cokrodiningratan dan Gowongan memiliki 
harkat sedang karena profil sungai wilayah ini masih dalam dan tidak melebar ke arah permukiman walaupun seluruh bantaran sungai juga sudah digunakan untuk permukiman. Akan tetapi jarak antara permukaan sungai dengan tebing sungainya di atas 25 meter. Seperti yang terlihat dari atas jembatan Gondolayu, ketinggian tebing sungai mencapai 55 meter, akan tetapi lebar sungai hanya 25 meter. Hal ini mampu didukung oleh kemiringan lereng sungai di atas $10 \%$ sehingga arus sungai bisa cepat.

Di wilayah Gowongan, seperti yang terlihat dari jembatan Kewek, ada luapan/ limpasan material lahar dingin yang masuk ke dalam permukiman di sebelah barat sungai hal ini disebabkan adanya sinusitas sungai (kelokan) yang tiba-tiba dari arah utara yang membelok ke arah Timur, dan didukung oleh kemiringan lereng sungai yang hanya $5 \%$. Walapun didukung oleh lebar sungai yang mencapai $57 \mathrm{~m}$, akan tetapi banyaknya gosong sungai yang ada di tengah aliran menyebabkan terjadinya luapan.

Berbeda halnya dengan 6 wilayah yang dijadikan sampel yaitu: wilayah Sosromenduran, Suryatmajan, Prawirodirjan, Keparakan, Brontokusuman, dan Sorosutan yang mempunyai harkat rentan terhadap bahaya banjir lahar hujan. Hal ini didukung oleh kemiringan lereng sungai yang di bawah 5\% dan banyaknya permukiman yang menjorok ke aliran Sungai
Code, walaupun telah ditanggul. Seperti yang terlihat di wilayah Prawirodirjan dan Keparakan lebar sungai ketika diukur hanya sekitar 42 m, dengan kedalaman tidak lebih dari 5 meter sehingga daya tampung aliran akan semakin kecil. Wilayah ini ketika tahun 2011 paling parah dampaknya karena seluruh material yang terbawa aliran sungai masuk kedalam permukiman, hal ini karena dam Brontokusuman telah penuh dengan material.

Banyaknya sinusitas/kelokan sungai Code di wilayah Selatan Kota Yogyakarta menambah tingkat kerentanan terjadinya erosi tebing sungai yang bersifat horisontal yang membuat longsor kawasan padat penduduk di kawasan bantaran Sungai Code di wilayah Sorosutan. Penataan yang telah dilakukan dengan pembuatan tanggul sungai dan penghijauan cukup membuat kawasan bekas bencana menjadi lebih indah walaupun tingkat kesadaran masyarakat yang masih rendah untuk tidak membuang sampah dan limbah rumah tangga ke badan sungai.

Sepanjang bantaran Kali Code di wilayah Kota Yogyakarta merupakan daerah sangat padat penduduk. Sebagian besar adalah orang-orang yang berasal dari luar Kota Yogyakarta. Salah satu contoh di wilayah Tegalpanggung, Jambon, Prawirodirjan, Keparakan, dan Karangkajen minim akan ruang terbuka hijau seperti taman atau areal dengan tanaman-tanaman. Jalan akses di 
wilayah ini juga tergolong sempit dan hanya cukup untuk dilalui kendaraan roda dua.

Kepadatan di sepanjang bantaran Kali Code menjadi lebih parah ketika kondisi berubah saat musim penghujan tiba. Secara daur hidrologi, hujan akan turun pada wilayah daratan yang dapat menjenuhkan kumpulan uap air di awan. Saat hujan turun di puncak Merapi yang merupakan hulu Kali Code, kemudian menghanyutkan material vulkanik sisa erupsi Gunung Merapi dan mengalir bersama run off melewati Kali Code. Debit air sungai yang tinggi serta viskositas air akibat kandungan material yang tinggi kerap menyusahkan warga. Banjir lahar dingin tidak hanya membawa bencana bagi warga tetapi juga perhatian pemerintah DIY. Melihat kondisi banjir lahar dingin yang datang setiap tahun pemerintah Kota Yogyakarta mulai membuat rencana revitalisasi kawasan pemukiman Kali Code agar lebih terarah dan aman dari bencana. Sebuah langkah yang dianggap solutif untuk meminimalisir kerugian dan korban, dan dikatakan sebuah mitigasi yang terencana. Yakni program revitalisasi pembangunan dari kebijakan ini masih terus berjalan.

Setiap pertambahan penduduk, secara otomatis akan memanfaatkan areal lain yang masih dianggap kosong untuk tempat hidup, serta memanfaatkan sumber daya demi keberlanjutan hidup. Faktor penduduk yang bertambah baik dalam kuantitas dan kualitas memiliki kemampuan mengeksploitasikan sumber daya alam sehingga mengancam lingkungan (Salim, 2010). Langkah yang harus dilakukan adalah relokasi dan kawasaan tersebut ditata kembali dengan perencanaan dan desain yang berbeda.Sehingga revitalisasi tetap berjalan dan kawasan tersebut tidak kehilangan nilai sebagai wilayah permukiman. Namun, permukiman yang sudah tidak terkena dampak bencana perlu tetap ada kawasan penghijauannya. Adapun revitalisasi yang dilakukan yaitu revitalisasi horizontal dan revitalisasi vertikal.

Revitalisasi kawasan pemukiman Kali Code ini sudah pernah dilakukan pada tahun 1983. Berdasarkan interview singkat penduduk asli yang mendiami wilayah sekitar Kali Code. Kawasan ini awalnya adalah rumah-rumah kumuh yang didiami oleh pekerja dan buruh kasar dengan kondisi lingkungan yang sangat tidak sehat. Sampai seorang sesepuh bernama Romo Mangun menggalakkan revitalisasi bagi rumah penduduk.

Proses penataan rumah-rumah berlangsung tanpa perencanaan. Bangunan berdiri secara spontan mengikuti aliran sungai atau lazim disebut pola linier. Pola seperti ini bertahan sampai sekarang seiring dengan pembangunan dan menghasilkan dampak positif pada kehidupan sosial penduduknya. Analisis sosial diperlukan di antaranya untuk mengetahui dampak sosial yang akan 
muncul akibat pembangunan (Kodoatie \& Sjarief, 2003).

Namun kekurangan dari pola linier ini secara berkala dirasakan ketika bencana banjir lahar dingin datang, pihak yang mengalami kerugian sangat banyak akibat rumah-rumah mereka yang benar-benar di bantaran sungai. Melihat seringnya bencana ini datang, revitalisasi dengan inovasi baru menjadi pilihan supaya dapat menghentikan kerugian akibat bencana.

Pembangunan rumah susun yang tidak jauh dari rumah asal penduduk sekitar Kali Code menjadi sebuah solusi yang dapat berdampak positif. Pasalnya kondisi mereka tidak lagi linier mengikuti arah aliran sungai, tetapi vertikal ke atas. Kondisi rumah yang bersusun ke atas dengan kondisi fisik bangunan baru yang kokoh dapat mengubah cara hidup masyarakat agar lebih sehat dan jauh dari bencana banjir lahar dingin. Sebuah solusi yang dilakukan untuk mengatasi permasalahan yang terjadi berulang.

Revitalisasi horizontal yaitu dengan rekayasa permukaan lahan dan diimbangi dengan keberadaan tumbuhan. Langkah pertama dari pengurangan dampak banjir adalah pembuatan lereng di pinggir sungai, biasanya dengan penghijauan atau penanaman tumbuhan-tumbuhan penutup lahan sehingga meningkatkan angka infiltrasi dan mengurangi produksi dari aliran permukann (Strahler, 1973).
Dikatakan horizontal yaitu pelaksanaannya dilaksanakan mengikuti aliran sungai dan berada pada sisi atau bantaran sungai. Tumbuhan penutup lahan ditanam dan dijadikan frontliner terhadap aliran banjir sebelum sampai kepada manusia. Fungsinya menyerap air dan meningkatkan infiltrasi, juga sebagai filter material vulkanik yang dibawa oleh arus sungai yang deras.

Langkah untuk meminimalkan dampak negatif akibat banjir lahar di bantaran Kali Code di Kota Yogyakyakarta di antaranya adalah pemetaan unsur-unsur rawan atau rentan, pemetaan daerah-daerah luapan air/jalur banjir, pemetaan silang bencanabencana, pengaturan tata guna lahan, pengurangan kepadatan penduduk dan bangunan, larangan penggunaan lahan bantaran kali untuk penggunaan tertentu, pemindahan lokasi unsur-unsur yang menghalangi arus banjir, pengaturan tentang bahan-bahan bangunan yang boleh digunakan, penepatan jalur pengungsian yang aman, dan penetapan dan sosialisasi level status sungai.

\section{SIMPULAN}

Kerentanan bencana banjit lahar dingin di sepanjang bantaran Sungai Code menunjukkan ada di beberapa wilayah yang mempunyai kategori sedang dan rendah. Wilayah yang mempunyai kategori sedang antara lain di wilayah Cokrodiningratan dan 
Gowongan. Sedangkan yang kategori rentan di wilayah Sosromenduran, Sur-yatmajan, dan Prawirodirjan. Upaya penanggulangan yang dilakukan oleh pemerintah Kota Yogyakarta adalah melalui revitalisasi kawasan pemukiman Kali Code yang meliputi revitalisasi horisontal dan revitalisasi vertikal.

\section{DAFTAR PUSTAKA}

Asdak, C. (2002). Hidrologi dan pengelolaan daerah aliran sungai. Yogyakarta: Gadjah Mada University Press.

Kodoatie, R. J., \& Sjarief, R. (2010). Tata ruang air. Yogyakarta: Penerbit Andi.
Maryono, A. (2005). Menangani banjir, kekeringan dan lingkungan. Yogyakarta: Gadjah Mada University Press.

Salim, E. (2010). Ratusan bangsa merusak satu bumi. Jakarta: Kompas Gramedia.

Siswoko. (2002). Banjir, masalah banjir dan upaya mengatasinya. Himpunan Ahli Teknik Hidroulika Indonesia (HATHI), Jakarta.

Strahler, A. N., \& Strahler, A. H. (1973). Environmental geoscience: Interaction between natural systems and man. Santa Barbara, California: Hamilton Publishing. 